\title{
Morphogenesis of sporotrophophyll leaves in Platycerium bifurcatum depends on the red/far-red ratio in the light spectrum
}

\author{
Jakub Oliwa $^{1} \cdot$ Andrzej Kornas $^{1} \cdot$ Andrzej Skoczowski $^{1}$
}

Received: 13 March 2016/Revised: 1 June 2016/Accepted: 15 September 2016/Published online: 27 September 2016

(C) The Author(s) 2016. This article is published with open access at Springerlink.com

\begin{abstract}
Although the fern Platycerium bifurcatum is popular among the producers of ornamental plants, it is a species of relatively poorly known physiology. Studies concerning the impact of the red/far-red (R/FR) ratio on photomorphogenesis refer primarily to spermatophytes. However, quite different phytochrome response mechanism functions in ferns, involving the localization of physiologically active form of phytochrome in the cytoplasm, without translocation to the nucleus. This work determined the reaction of young fern sporotrophophylls to the change of the R/FR ratio and investigated sporophyte ontogeny in various spectral light composition using nondestructive testing methods. It has been shown that the development of morphogenic sporophyte depends on the R/FR ratio. At a high R/FR ratio, sporotrophophylls showed a slower growth compared to those growing at a low value. A high R/FR value resulted in lower photochemical performance of PSII and adverse changes in the functioning of the acceptor portion of the PSII reaction center, while the PSII vitality analysis indicated the positive effect of simulated shadow. The value of the R/FR ratio did not affect the intensity of blue-green leaf fluorescence. However, the fluorescence intensity of red and far-red was significantly higher in plants growing at higher $\mathrm{R} / \mathrm{FR}$ values. The analysis of leaf optical properties indicated higher concentrations of carotenoids and anthocyanins in the leaves of plants grown under the lower R/FR
\end{abstract}

Communicated by U. Feller.

Andrzej Kornas

kornasandrzej@gmail.com

1 Institute of Biology, Pedagogical University of Cracow, Podchorążych 2, 30-084 Kraków, Poland ratio. Determining the effect of spectral light composition on the physiology of this species may be useful for plant breeders and for the protection of these epiphytes in natural habitats.

Keywords Chlorophyll $a$ fluorescence · Fern · Photomorphogenesis - Reflectance - Spectral composition of light $\cdot$ Sporotrophophyll

\begin{tabular}{|c|c|}
\hline \multicolumn{2}{|c|}{ Abbreviations } \\
\hline Area & $\begin{array}{l}\text { Surface area above the chlorophyll fluorescence } \\
\text { induction curve }\end{array}$ \\
\hline ARI & Anthocyanin reflectance index \\
\hline BRFR & $\begin{array}{l}\text { Spectral composition containing blue, red and } \\
\text { far-red radiation }\end{array}$ \\
\hline $\mathrm{BR}$ & $\begin{array}{l}\text { Spectral composition containing blue, red with } \\
\text { lower intensity of far-red radiation }\end{array}$ \\
\hline $\mathrm{CRI}_{1}$ & Carotenoid reflectance index \\
\hline $\mathrm{DI}_{0} / \mathrm{RC}$ & $\begin{array}{l}\text { Total energy dissipation not trapped by the PSII } \\
\text { reaction center }\end{array}$ \\
\hline $\mathrm{ET}_{0} / \mathrm{RC}$ & $\begin{array}{l}\text { Rate of electron transfer by the active PSII } \\
\text { reaction center }\end{array}$ \\
\hline$F_{\mathrm{V}} / F_{0}$ & $\begin{array}{l}\text { Maximum efficiency of the water splitting } \\
\text { reaction of the donor side of PSII }\end{array}$ \\
\hline$F_{\mathrm{V}} / F_{\mathrm{M}}$ & Maximum quantum yield of PS II \\
\hline $\mathrm{H}-\mathrm{R} / \mathrm{FR}$ & Higher value of the red/far-red ratio \\
\hline L-R/FR & Lower value of the red/far-red ratio \\
\hline NIR & Near-infrared range in the light spectrum \\
\hline PAR & Photosynthetically active radiation \\
\hline PI & PSII vitality index \\
\hline PRI & Photochemical reflectance index \\
\hline PSII & Photosystem II \\
\hline $\mathrm{Q}_{\mathrm{A}}$ & Plastochinon $\mathrm{Q}_{\mathrm{A}}$ \\
\hline $\mathrm{RC}$ & Reaction center \\
\hline
\end{tabular}


RC/ABS Reaction center density ratio in terms of chlorophyll

R/FR Photon intensity between 660 and $670 \mathrm{~nm} /$ photon intensity between 725 and $735 \mathrm{~nm}$

$\mathrm{TR}_{0} / \mathrm{RC} \quad$ Energy trapping of one active reaction center WBI Water band index

\section{Introduction}

The results of many experiments show that spectral composition, in addition to the main factor, i.e., light intensity, plays a particular role in photomorphogenesis. Solar radiation enables plants to initiate specific metabolic pathways associated with acclimation to changing environmental conditions already at an early stage of ontogeny. The corresponding proportions of individual light wavelengths carry biologically useful information about conditions of external environment and regulate the process of tissue morphogenesis (Kraepiel et al. 2001). A key role is played by the ratio of red to far-red light (R/FR), informing plants about changes occurring in their environment. It determines specific physiological reactions and, in consequence, sometimes also morphological responses (Fankhauser 2001). Phytochromes, often referred to as "photomorphogenetic pigments" are primarily responsible for the absorption of red and far-red wavelengths (Quail 1994). Phytochrome photoperception is a common mechanism for the detection of red and far-red light in bacteria, cyanobacteria, fungi and plants (Rösler et al. 2010). Plant responses to changes in the R/FR ratio at the cellular level are associated with changes in gene expression and initiation of many metabolic pathways, acting as signal functions for photomorphogenetic processes (Kircher et al. 1999; Neff et al. 2000). The phytochrome reaction mechanism in ferns, mosses and certain algae differs when compared to spermatophytes. The main difference is related to the lack of translocation of part of the phytochrome pool activated by red light from the cytoplasm to the nucleus (Wada 1988; Rösler et al. 2010). In different fern species growing in low-light conditions, chimeric (hybrid) photoreceptors, combining the properties of phytochrome and phototropin, can play an important role in ontogeny in the processes regulating morphogenesis through red and far-red light (Kawai et al. 2003).

Both the intensity and spectrum of sunlight are subject to constant changes in the Earth's atmosphere. This is due to the dynamic changes of atmosphere components both natural (carbon dioxide, water vapor, ozone) as well as contaminants (e.g., particulates) and weather conditions (cloud cover). Moreover, part of the radiation is reflected from leaf surfaces and their cellular structures (Taiz and Zeiger 2006). In addition, the architecture of individual plants, complex structure of canopy and forest layers result in heterogeneous illumination of individual organs in terms of light spectral composition and its intensity. This particularly applies to plants growing in the lower layers of the forest where the tree crowns regulate lighting, temperature and humidity, and induce the formation of specific microclimates (Nadkarni et al. 2004). This applies mainly to the R/FR ratio, the value of which decreases with the distance from the top of the canopy. The increasing human activity in rainforests causes degradation of these local ecosystems and fluctuations in the intensity of impact of abiotic factors, including light. This is particularly important for epiphytic plants, living under the tree crowns, such as the fern Platycerium.

The genus Platycerium is one of the few pantropical epiphytic fern genera with six species in Afro-Madagascar, 8-11 Australasian species, and a single species in tropical South America (Kreier and Schneider 2006). This genus belongs to the class of leptosporangiate ferns, extremely diverse in terms of structure. In addition to the plants of typical herbaceous sporophyte, it also includes woody plants and epiphytes. The unusual nature of ferns morphology explains the classification of Platycerium bifurcatum into the latter group.

The mature form of sporophyte is characterized by two types of leaves: sporotrophophyll and nest leaves. Nest leaves are responsible for keeping the plant on the trunk as well as humus and water accumulation, while green sporotrophophyll leaves play basic assimilation functions. Their size in mature plants usually ranges between 25 and $90 \mathrm{~cm}$ (Jones and Goudey 1981). They adapt band-like shape, with dichotomously forked ending, on which sporangia are located on the lower lamina surface.

Despite the extraordinary popularity of this species, mainly due to its esthetic values, the physiology of $P$. bifurcatum is relatively poorly understood. Physiological studies conducted so far have been mainly limited to determination of the response of this plant to drought stress and a description of micropropagation methods for commercial purposes (Rut et al. 2003; Aspiras 2010, Liao and $\mathrm{Wu}$ 2011). In recent years, research has been initiated on the effects of light intensity on the functioning of photosynthetic apparatus of $P$. bifurcatum (Sanusi et al. 2011), which natural habitats are increasingly exposed to stress radiation. It is associated with increased anthropogenic pressure in the areas of its occurrence, particularly with rainforest deforestation.

The present study analyzed changes in the morphology of young $P$. bifurcatum sporophyte and photochemical efficiency of sporotrophophyll leaves in relation to the $\mathrm{R} / \mathrm{FR}$ ratio of light reaching the plants. This value provides information about the intensity of light in the growth environment, i.e., shading or insolation-low (L) or high 
(H) $\mathrm{R} / \mathrm{FR}$, respectively. Plant response to the $\mathrm{R} / \mathrm{FR}$ ratio is a key element of the so-called strategy of shade avoidance. Considering the information on the sensitivity of plants of the genus Platycerium to the high light intensity (Sanusi et al. 2011), it was investigated whether an increase in the $\mathrm{R} / \mathrm{FR}$ ratio affected the process of photomorphogenesis of $P$. bifurcatum sporophytes. The applied experimental conditions allowed to trace the differences in sporophyte ontogeny in various light spectral compositions. The advantage of this study was the sole use of non-destructive research methods, allowing to track the progressive physiological changes during ontogeny in the same leaves.

\section{Materials and methods}

\section{Plant material}

The study was performed on 10-month sporophytes of Platycerium bifurcatum (Cav.) C. Chr., derived from the collection of the Institute of Biology at the Pedagogical University in Cracow. One month before the start of the measurements, 22 best developed, morphologically similar young sporophytes were selected. They were placed in a Flowstar Snijders Scientific phytotron chamber (The Netherlands) for acclimation. Half of the plants were exposed to the light with a BRFR spectral composition, with an equal LED number, emitting radiation of 450, 650, and $730 \mathrm{~nm}$ wavelengths and a light intensity of 5000 , 13,000 , and $7000 \mathrm{~cd} \mathrm{sr} \mathrm{m}^{-2}$, respectively. This enabled to obtain the low-red to far-red ratio-L-R/FR - and simulate shadow conditions (Fig. 1). Other plants were grown under the BR light with significantly lower intensity of the far-red radiation (700-780 $\mathrm{nm}$ range) and a slightly increased radiation intensity in the blue wavelength range to

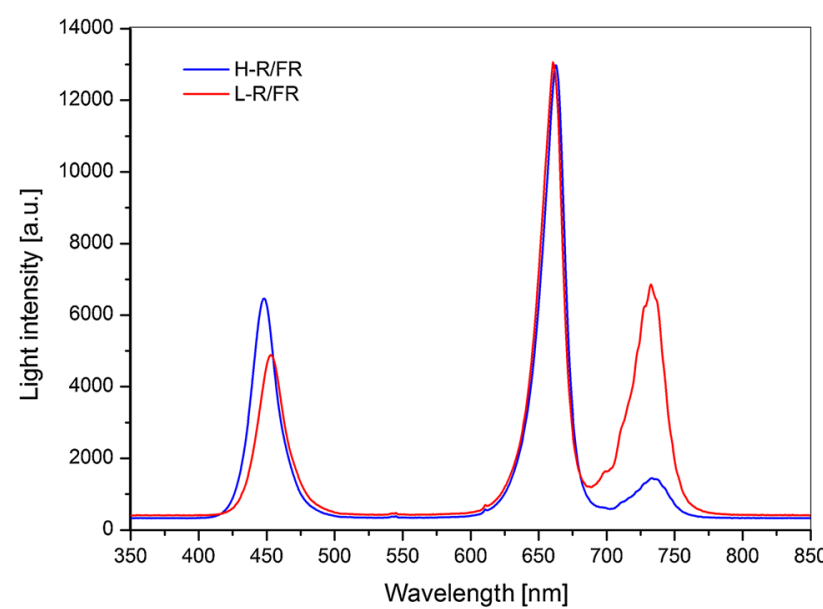

Fig. 1 The intensity of the light radiation at different wavelengths at a high (H-R/FR) and low (L-R/FR) value of R/FR compensate for the amount of light energy reaching the plants. This way, the higher value of R/FR was obtainedH-R/FR (Fig. 1), characteristic of well-insolated habitats. Sporophytes grew at a photoperiod of $16 / 8 \mathrm{~h}$ at $25 / 15^{\circ} \mathrm{C}$ (day/night, respectively). RH was set to $60 \%$.

All measurements were performed at 1 and 3 months of exposure to described spectral conditions. Each time, the analyses were conducted on the same sporotrophophyll leaves, which allowed to track physiomorphological changes occurring during sporophyte ontogenetic development without inter-individual variability.

\section{Microscopy analysis}

Hand-cut pieces of lamina were observed in distilled water using a Nikon ECLIPSE Ni light and epifluorescence microscope (Nikon, Japan) equipped with Microscope Camera Digital Sight series DS-Filc and NIS Imaging software, Nikon version 4.11.

\section{PSII photosynthetic efficiency evaluation}

Chlorophyll $a$ fluorescence was measured using a HandyPEA Hansatech Instruments fluorometer (UK) according to the method of Strasser et al. (2000). Non-invasive measurements after the first and third month of development were carried out on the upper side of the same leaf lamina, at $20{ }^{\circ} \mathrm{C}( \pm 1)$. Before the measurement, to quench chlorophyll fluorescence, the plant was acclimated to the dark for $20 \mathrm{~min}$. Radiation of $3 \mathrm{mmol}$ (quantum) $\mathrm{m}^{-2} \mathrm{~s}^{-1}$ was used for the excitation of chlorophyll fluorescence. The measurement results were analyzed using PEA Plus Hansatech Instruments software (UK). General fluorescence parameters were analyzed: $F_{V} / F_{M}$-maximum photochemical efficiency of PSII (Bjorkman and Demming 1987) and Area, which defines the area above the fluorescence curve and illustrates the Kautsky effect. It is also used to determine the pool of available PSII acceptors. The following parameters of photosynthetic apparatus efficiency were determined: maximum efficiency of the water splitting complex on PSII donor side $\left(F_{V} / F_{0}\right)$, PSII vitality (PI) and photosynthetic performance index, showing reaction center density in terms of chlorophyll-RC/ABS (Strasser et al. 2000). Energy flow through PSII was evaluated on the basis of three flow parameters: $\mathrm{TR}_{0} / \mathrm{RC}$ energy trapping of one active reaction center, $\mathrm{ET}_{0} / \mathrm{RC}-$ rate of electron transfer through active $\mathrm{RC}, \mathrm{DI}_{0} / \mathrm{RC}$ - total energy dissipation, not trapped by RC.

\section{Fluorescence emission spectra of leaves}

Fluorescence spectra of $P$. bifurcatum leaves were obtained using a Perkin Elmer LS55 spectrofluorometer (USA) with 
FL WinLab software version 4.0. Measurements were performed at $20^{\circ} \mathrm{C}$, on the upper lamina surface, with an external fiber optic accessory (L2250144) ending with a measurement clip. The slots of excitation and emission radiation were set to $9 \mathrm{~mm}$. The use of external fiber optic accessory enabled non-invasive measurements, i.e., without the need of damaging the leaves. Fluorescence emission spectra of the leaves were measured in dual band radiation according to the method described by Lichtenthaler and Schweiger (1998). The blue-green range (430-650 nm) allowed to determine fluorescence intensity of phenolic compounds, and red with far-red (600-800 nm) to observe chlorophyll fluorescence. The beam at wavelengths of 390 and $440 \mathrm{~nm}$ was used to induce fluorescence.

Indices evaluating the impact of environmental factors on the metabolism of plants were calculated based on the following fluorescence spectra: F450/F530, F450/F684, F450/F735, and F684/F735 (where $F$ is the fluorescence intensity at a given wavelength).

\section{Optical properties of leaves}

The reflectance spectrum of the light radiation in the range of 400-1000 nm was measured using a CID Bio-Science CI-710 spectrometer (USA) with SpectraSnap software. Measurements were performed after 1 and 3 months of plant growth under different spectral conditions. The reflectance was measured on the upper surface of the lamina at $20{ }^{\circ} \mathrm{C}$.

Reflectance indices were calculated on the basis of reflectance spectra allowing to assess changes in the content of anthocyanins and carotenoids (ARI, CRI ${ }_{1}$ ) and water (WBI) in the leaves. The PRI index, indicative of light use efficiency by the leaves in the PAR range (LUE) was also calculated.

$$
\begin{aligned}
& \mathrm{CRI}_{1}=\left(R_{520}^{-1}-R_{550}\right)^{-1} \times R_{800} \quad(\text { Gitelson et al. 2002) } \\
& \mathrm{ARI}=\left(R_{550}{ }^{-1}-R_{700}\right)^{-1} \times R_{800} \quad(\text { Gitelson et al. 2001) } \\
& \mathrm{PRI}=\left(R_{570}-R_{531}\right) \cdot\left(R_{570}+R_{531}\right)^{-1} \quad(\text { Gamon et al. 1992) } \\
& \mathrm{WBI}=R_{900} \cdot R_{970}{ }^{-1} \quad \text { (Peñuelas et al. 1993) }
\end{aligned}
$$

The letter $R$ in equations is the reflectance intensity at the radiation wavelength given in subscript.

\section{Statistical analysis}

The resulting numerical data were subjected to statistical analysis (ANOVA) using StatSoft, Inc. (2014); STATISTICA (data analysis software system), version 12 . www.statsoft.com. The significance of the differences was determined at $P \leq 0.05$ by Duncan test.

\section{Results and discussion}

\section{Morphology and anatomy of leaves}

Sporophyte ontogenetic development is primarily based on the increase of assimilation surface, lamina thickness and formation of characteristic dichotomous forks in the apical part. These changes are accompanied by the emergence of stellate, dead trichomes on epidermis, forming tomentose. It protects the leaves from overheating in strong sunlight and absorbs water. As the leaf grows, tomentose structure becomes less compact, and disappears in some areas. However, in the mature plants (approx. 10-year-old specimens) it covers almost the entire surface of the lamina. After the first month of development under H-R/FR, tomentose is less developed, and during further ontogeny it disappears faster than that of plants grown under L-R/FR.

Sporotrophophyll leaf anatomy did not significantly differ at 1 and 3 months of growth in both spectral light compositions (Fig. 2). Relatively large cells accumulating water are located directly under the upper epidermis. Palisade parenchyma with numerous chloroplasts is located deeper, underneath it is the spongy parenchyma, bordering with the lower epidermis and also containing chloroplasts. Vascular bundle, surrounded by endoderm, is located in the central part of the cross section. Sclerenchyma cells are present on both sides of it.

Anatomical studies were performed because the spatial structure of parenchyma cells strongly depends on the light conditions. The leaves of plants adapted to low-intensity radiation are characterized by a thinner mesophyll layer of looser structure. Then, only one layer of the palisade parenchyma is present and the number of chloroplasts is typically smaller compared to leaves grown under intensive light (Lambers et al. 2008). The spongy parenchyma is well developed in plants growing in the shade, as it lengthens the path of light in the leaf through reflection at the interface and increases the absorption capacity of leaves (Vogelmann et al. 1996). When the intensity of radiation is increased, the acclimation potential of leaves growing in the shade is limited by their anatomical structure and the presence of intercellular space in mesophyll (Oguchi et al. 2005). Therefore, a complete acclimation sometimes requires production of entirely new leaves by the plant (Lambers et al. 2008). However, as mentioned above, no anatomical changes were found resulting from alterations in the R/FR ratio in $P$. bifurcatum plants.

Change in the spectral composition of light, reaching young sporophytes, affects leaf growth rate. Plants growing in shadow-simulating conditions, i.e., at the low value of R/FR (L-R/FR), reached significantly larger sizes (Fig. 3b), 

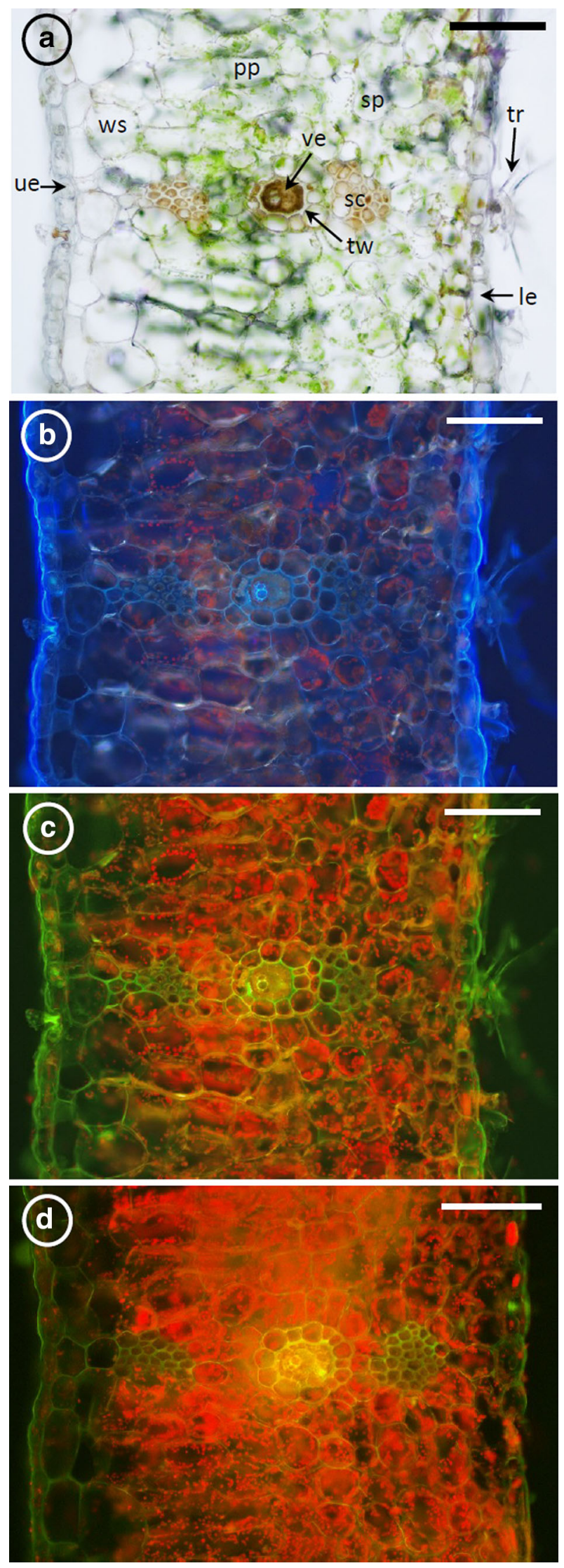

४Fig. 2 Cross section of (a-c) one- and (d) three-month-old sporotrophophyll leaves of Platycerium bifurcatum (the elkhorn fern or the staghorn fern). a Observed in transmitted white light. b-d Observed using epifluorescence microscopy. Red, green and blue colors correspond to autofluorescence of chlorophyll and cell walls, respectively. ue upper epidermis, le lower epidermis, ws waterstorage tissue, $p p$ palisade parenchyma, $s p$ spongy parenchyma, ve vein, $s c$ sclerenchyma, tw thickened inner walls (arrows) of the mesophyll cell bordering with the endodermis, $t r$ trichomes. Scale bar $200 \mu \mathrm{m}$

compared to those exposed to the high $\mathrm{R} / \mathrm{FR}$ radiation $(\mathrm{H}-$ R/FR) (Fig. 3a).

\section{Photosynthetic efficiency of leaves}

Quantum yield of photosynthesis can be determined based on the $F_{V} / F_{M}$ parameter, which allows to assess changes in the functioning of PS II (Naumann et al. 2008). A significant decrease in the PSII photochemical efficiency was recorded in plant leaves exposed to H-R/FR after 3 months of growth compared with that observed after 1 month (Table 1). Sanusi et al. (2011) demonstrated that longer exposure of $P$. bifurcatum to intense sunlight above $200 \mu \mathrm{mol}$ (quantum) $\mathrm{m}^{-2} \mathrm{~s}^{-1}$ contributed to the reduction of $F_{V} / F_{M}$, although it was not yet a sign of photoinhibition, which is diagnosed only at the PAR intensity of $1500 \mu \mathrm{mol}$ (quantum) $\mathrm{m}^{-2} \mathrm{~s}^{-1}$. This allowed to conclude that the plants growing under $\mathrm{H}-\mathrm{R} /$ FR responded to the information about a higher light energy dose. It should be noted that the natural habitat of this fern species is characterized by a high shading, and thus more light waves in the far-red range (L-R/FR).

Area values (Table 1) suggested that the energy transfer to plastoquinone $\mathrm{Q}_{\mathrm{A}}$ from PSII active center was not inhibited and increased during leaf development. This proved the acclimation of plants to spectral conditions and the occurrence of growth processes, during which the increase in area values seemed to be a natural phenomenon resulting from an increase in the $\mathrm{Q}_{\mathrm{A}}$ pool.

According to some authors (Pereira et al. 2000, Oliveira et al. 2002, Paiva et al. 2009), the $F_{V} / F_{0}$ parameter is more sensitive in determining PSII efficiency than the photochemical performance index $\left(F_{V} / F_{M}\right)$. A decrease in this value indicates disturbances in the functioning of extremely sensitive to environmental changes, water splitting complex (Pereira et al. 2000). The stability of this complex affects plant resistance (Jiang et al. 2006). The general trend of changes in $F_{V} / F_{0}$ is similar to $F_{V} / \mathrm{F}_{\mathrm{M}}$ and indicates slight unfavorable changes in the functioning of the acceptor part of PSII reaction center (Table 1). These changes occur during the increase at H-R/FR (higher insolation), with no statistically significant differences between the plants growing under L-R/FR conditions 
a
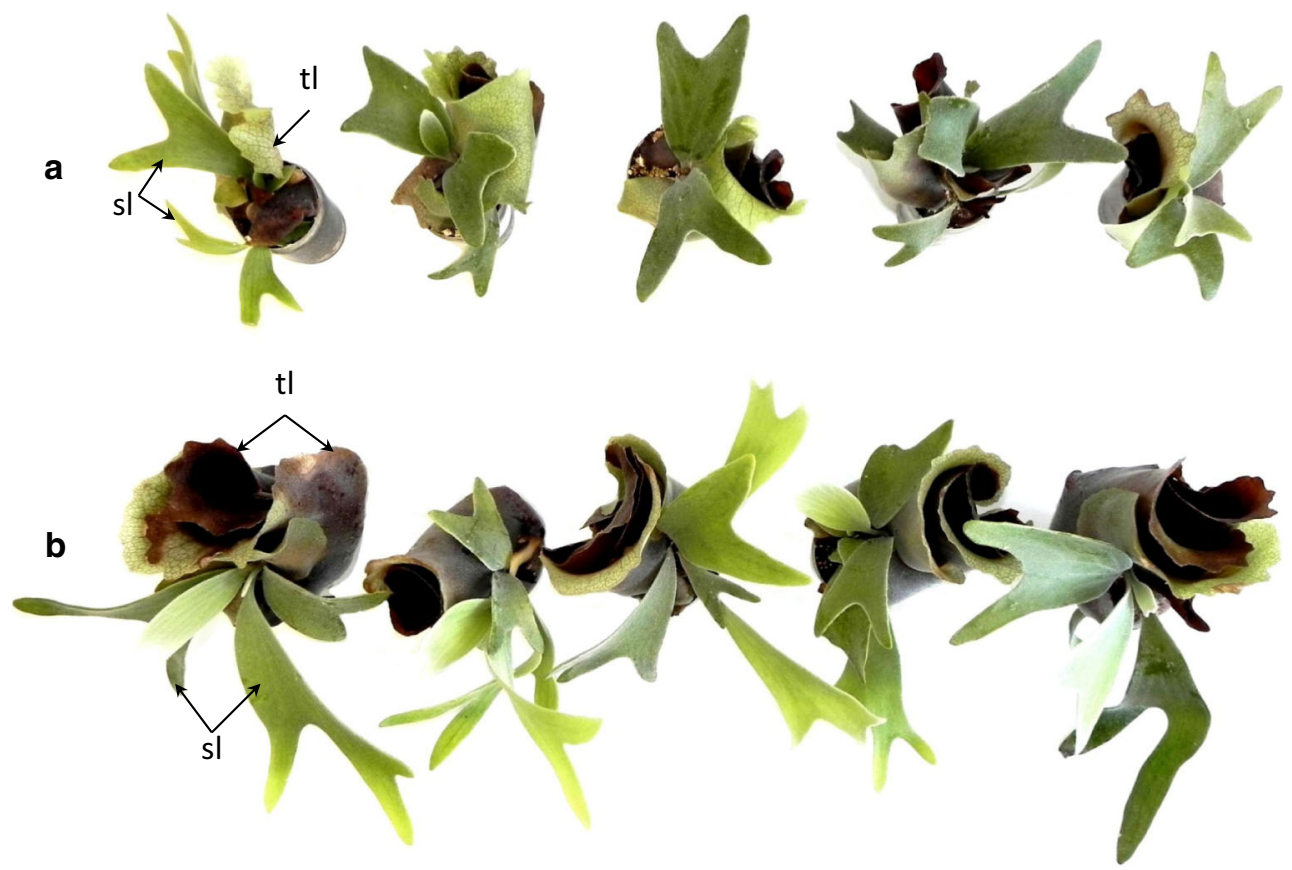

Fig. 3 Size of 12-month sporophytes of Platycerium bifurcatum after 3 months of growth under a high (H-R/FR), b low (L-R/FR) R/FR value. $s l$ sporotrophophyll, $t l$ trophophyll

Table 1 The values of chlorophyll $a$ fluorescence parameters at 1 and 3 months of growth of Platycerium bifurcatum sporotrophophyll leaves at low (L-R/FR) and high (H-R/FR) red/far-red ratio (R/FR)

\begin{tabular}{|c|c|c|c|c|c|c|c|c|c|}
\hline \multirow[t]{2}{*}{$\mathrm{R} / \mathrm{FR}$ ratio } & \multirow[t]{2}{*}{ Growth time (month) } & \multicolumn{8}{|c|}{ Chlorophyll $a$ fluorescence parameters } \\
\hline & & $F_{V} / F_{M}$ & Area & $F_{V} / F_{0}$ & PI & $\mathrm{RC} / \mathrm{ABS}$ & $\operatorname{Tr}_{0} / \mathrm{RC}$ & $\mathrm{Et}_{0} / \mathrm{RsC}$ & $\mathrm{Di}_{0} / \mathrm{RC}$ \\
\hline \multirow[t]{2}{*}{ L-R/FR } & 1 & $0.78 \mathrm{a}$ & $18880 \mathrm{~b}$ & $3.61 \mathrm{a}$ & $2.87 \mathrm{c}$ & $1.21 \mathrm{ab}$ & $672 \mathrm{a}$ & $664 a$ & $202 \mathrm{a}$ \\
\hline & 3 & $0.77 \mathrm{a}$ & $59456 a$ & $3.11 \mathrm{a}$ & $2.65 \mathrm{bc}$ & $1.64 b c$ & $1539 b$ & $1482 b$ & $503 b$ \\
\hline \multirow[t]{2}{*}{ H-R/FR } & 1 & $0.78 \mathrm{a}$ & $18936 b$ & $3.77 \mathrm{a}$ & $1.65 \mathrm{ab}$ & $0.94 \mathrm{a}$ & $763 a$ & $702 \mathrm{a}$ & $203 \mathrm{a}$ \\
\hline & 3 & $0.66 b$ & $51806 a$ & $1.98 \mathrm{~b}$ & $1.44 \mathrm{a}$ & $1.79 \mathrm{c}$ & $990 \mathrm{a}$ & $1035 a$ & $565 \mathrm{c}$ \\
\hline
\end{tabular}

Values in the column marked with the same letters are not significantly different at $P \leq 0.05$ by Duncan test, $n=5$

(shadow). The vitality of PSII measured by the PI (Table 1) suggests a positive effect of the shadow (L-R/FR) on the efficiency of photosynthetic apparatus. This parameter demonstrates the inner strength of the plant that allows to counteract external stressors. It depends on the number of active reaction centers, quantum yield of photosynthesis and the course of redox reactions in the dark phase (Strasser et al. 2000, 2004). In this case, both after 1 and 3 months of growth, a higher vitality of plants was observed growing under L-R/FR (increased PI) than those under H-R/FR.

Together with lamina development, the density of reaction centers in terms of chlorophyll is also increasingRC/ABS (Strasser et al. 2000). The increase in this parameter occurred in both spectral light systems; however, it was statistically significant only for H-R/FR (Table 1).
This is understandable because in the conditions of intense radiation, chloroplasts with an extensive lamellar system are produced with a large number of thylakoid grana, leading to an increase in the number of PSII complexes and chlorophyll $a$ (Taiz and Zeiger 2006). A plant, when attempting to adjust to a higher energy dose, develops structures allowing for its increased absorption, which can be considered an acclimation to environmental conditions. However, too many RCs in relation to functional $\mathrm{Q}_{\mathrm{A}}$ cause a delay in the energy transfer (Strasser et al. 2000). The $\mathrm{TR}_{0} / \mathrm{RC}$ parameter indicates the maximum, possible after excitation, energy trapping by the PSII active reaction center. It is associated with the reduction in the plastoquinone $\mathrm{Q}_{\mathrm{A}}$ pool (Force et al. 2003). Hence, the value of this parameter in plants receiving information about H-R/ FR, despite the large pool of active centers, remains at a 
similar level, while the $\mathrm{TR}_{0} / \mathrm{RC}$ value increases in leaves growing in the shade (L-R/FR).

The rate of electron transfer through individual active reaction centers, expressed as $\mathrm{ET}_{0} / \mathrm{RC}$, strongly correlates with $\mathrm{TR}_{0} / \mathrm{RC}$ (Strasser et al. 2000). Therefore, it is not surprising that the trend of changes in both parameters was similar and the rate of energy transfer was higher in the leaves grown under L-R/FR. However, an increase in the number of RC during morphogenesis in the latter plants was not as sudden as in those exposed to $\mathrm{H}-\mathrm{R} / \mathrm{RF}$ radiation.

The $\mathrm{DI}_{0} / \mathrm{RC}$ parameter (Table 1) illustrates the total energy dissipation (mainly in the form heat), which is not trapped by the reaction center (Force et al. 2003). Statistical analysis showed that this dissipation was more increased during the plant growth under the H-R/FR than $\mathrm{L}-\mathrm{R} / \mathrm{FR}$ range. This is caused by the lower efficiency of energy transfer in plants growing under conditions simulating high insolation. The relationships between the flow parameters in this study are consistent with those obtained by Castro et al. (2011) and correspond to the assumptions proposed by Strasser et al. (2000).

\section{Blue-green and red fluorescence of leaves}

Main fluorescence emission bands of phenolic compounds, depending on the species, are usually located in the blue $(430-450 \mathrm{~nm})$ and green range $(520-530 \mathrm{~nm})$ (Lichtenthaler and Schweiger 1998). As regards P. bifurcatum, only peak shoulder was observed at a wavelength of $430 \mathrm{~nm}$ (Fig. 4). This might indicate a shift in the emission maximum in the blue spectrum towards shorter wavelengths. According to Johnson et al. (2000), who carried out experiments on 35 species from different plant taxa, blue fluorescence emission maximum is in the range of 405-475 nm. Moreover, slight shifts are dependent on the excitation wavelength. In comparison with the results of Lichtenthaler and Schweiger (1998), carried out on monoand di-cotyledonous species, a clear band in the green spectrum at $530 \mathrm{~nm}$ can be distinguished in P. bifurcatum. However, as demonstrated by Richter and Lichtenthaler (1996), specific growth conditions can cause an increase in the intensity of green fluorescence, sometimes even exceeding the peak maximum in the blue range.

Fluorescence in the red and far-red range derived from chlorophyll has two emission maxima in photosynthetic organisms in the range of approximately $685-690 \mathrm{~nm}$ and 735 nm (Gitelson et al. 1998; Hall and Rao 1999). However, changes in the course of fluorescence curves are largely dependent on the absorption properties of leaves (Gitelson et al. 1998) and changes in the kinetics of fluorescence induction, which is not observed in the blue-green spectrum (Stober and Lichtenthaler 1993).
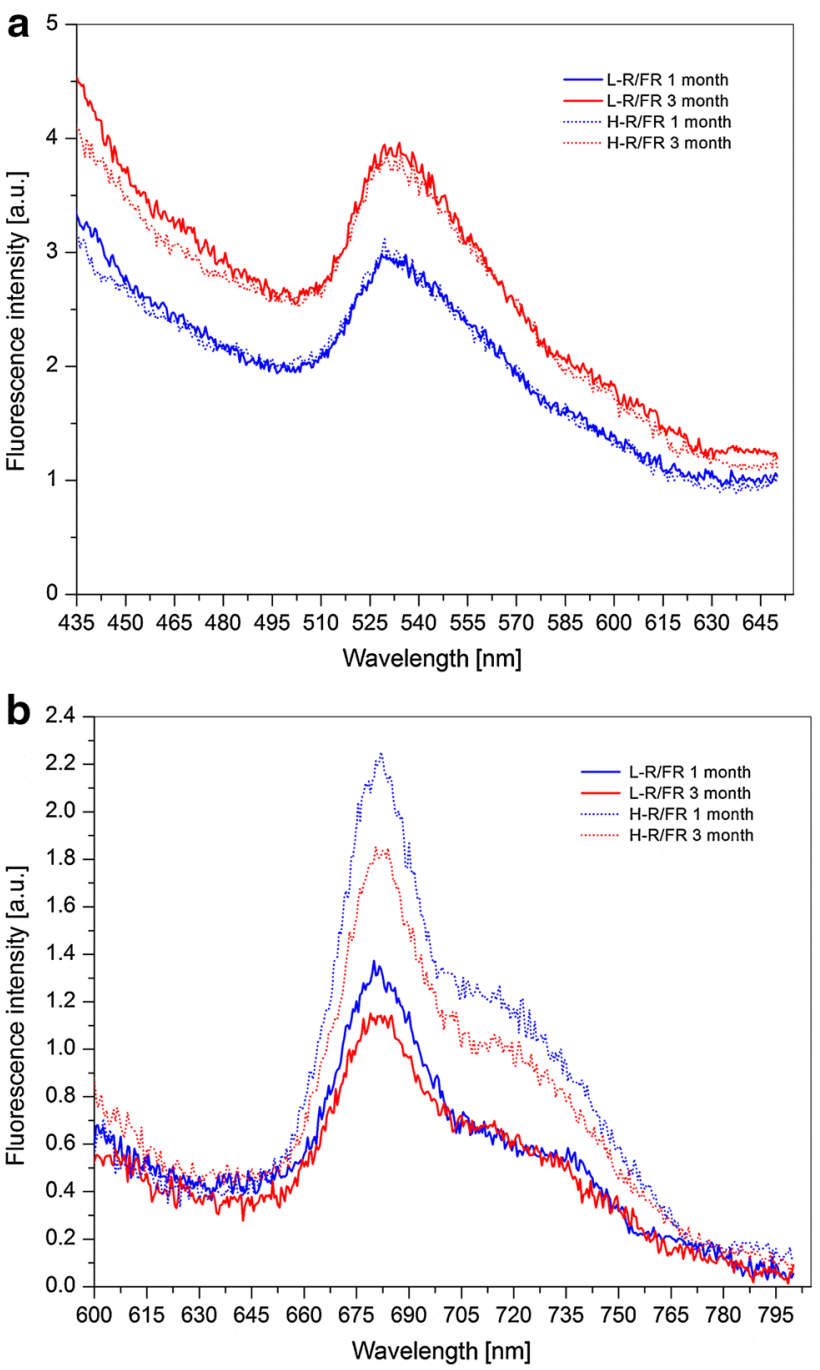

Fig. 4 Blue-green (a) and red (b) fluorescence spectra of sporotrophophyll leaves of Platycerium bifurcatum after 1 and 3 months of growth at low (L-R/FR) and high (H-R/FR) R/FR ratio in the light spectrum. The mean standard deviation for all points of each curve does not exceed $10 \%$. The curves represent mean values of 5 replicates

With the growth of the plants in both spectral conditions, an increase in the fluorescence intensity of phenolic compounds was observed in the cell wall (Fig. 4). However, there was no difference in the F450/F530 ratio, indicating similar content of phenolic compounds in the leaf epidermis (Table 2). The function of these compounds includes photoprotection of plants from strong UV radiation (Bilger et al. 2001). The light conditions applied did not cause radiation stress; therefore, lack of noticeable differences in this parameter in both plant groups was not surprising. The higher ratios of blue to red fluorescence (F450/F684), and blue to far-red (F450/F735), apparent between the first and third month of growth appeared to be the result of leaf ontogeny (Table 2). An increase in F450/ 
Table 2 The values of fluorescence parameters at 1 and 3 months of growth of Platycerium bifurcatum sporotrophophyll leaves at low (L-R/FR) and high (H-R/FR) red/far-red ratio (R/FR)

\begin{tabular}{llllll}
\hline R/FR ratio & Growth time (month) & \multicolumn{4}{l}{ Fluorescence ratios } \\
\cline { 3 - 6 } & & F450/F530 & F450/F684 & F450/F735 & F684/F735 \\
\hline L-R/FR & 1 & $0.917 \mathrm{a}$ & $0.833 \mathrm{a}$ & $2.127 \mathrm{~b}$ & $2.226 \mathrm{ab}$ \\
& 3 & $0.892 \mathrm{a}$ & $1.372 \mathrm{~b}$ & $5.007 \mathrm{a}$ & $1.856 \mathrm{ab}$ \\
$\mathrm{H}-\mathrm{R} / \mathrm{FR}$ & 1 & $0.951 \mathrm{a}$ & $1.464 \mathrm{ab}$ & $3.937 \mathrm{ab}$ & $2.469 \mathrm{~b}$ \\
& 3 & $0.960 \mathrm{a}$ & $5.315 \mathrm{c}$ & $8.370 \mathrm{c}$ & $1.752 \mathrm{a}$ \\
\hline
\end{tabular}

Values in the column marked with the same letters are not significantly different at $P \leq 0.05$ by Duncan test, $n=5$
F684 was observed after 3 months of growth both in plants cultivated under L-R/FR and H-R/FR. However, a significantly higher increase of the F450/F684 ratio (by approx. $260 \%$ ), which is a sensitive detector of early response to changes in the environment (Buschmann and Lichtenthaler 1998), was observed in plants growing under H-R/FR. A similar trend was observed with respect to the second factor-F450/F735, considered a sensitive indicator of changes in metabolic activity caused by environmental factors (Schweiger et al. 1996). The analysis of the F684/ F735 ratio is useful to monitor changes in the chlorophyll content during the plant growth as well as under unfavorable environmental conditions (D'Ambrosio et al. 1992, Tuba et al. 1993, Buschmann and Lichtenthaler 1998). This method was first introduced by Lichtenthaler et al. (1986) and can be considered reliable only if the concentration of chlorophyll in the leaves does not exceed $30 \mu \mathrm{g} \mathrm{cm}^{-2}$ (Gitelson et al. 1998). Under H-R/FR, the F684/F735 ratio between the first and third month of growth was decreasing, indicating a significant increase in chlorophyll content in the leaves. The value of this coefficient is in fact inversely proportional to chlorophyll content in the leaves (Gitelson et al. 1998). Under intense light associated with $\mathrm{H}-\mathrm{R} / \mathrm{FR}$, the development of granal thylakoids is a natural acclimation mechanism. This translates into a significant PSII quantity and a high content of chlorophyll $a$. It should be noted, however, that acclimation changes in chlorophyll content, induced by environmental factors, occur slowly (Moya and Cerovic 2004).

\section{Radiation reflectance of leaves}

Radiation reflectance curves of $P$. bifurcatum leaves had a similar pattern under both L-R/FR and H-R/FR (Fig. 5). A clearly marked band could be observed in the yellow-green range (approx. $550 \mathrm{~nm}$ ), similarly as in other plant species (Gitelson et al. 2001). After 1 month of growth under L-R/ FR, plants generally exhibited higher reflectance intensity in the PAR range than those grown under H-R/FR. After 3 months of growth, regardless of the R/FR value, radiation reflectance intensity was lower than that observed after 1 month. Between the first and third month of growth,

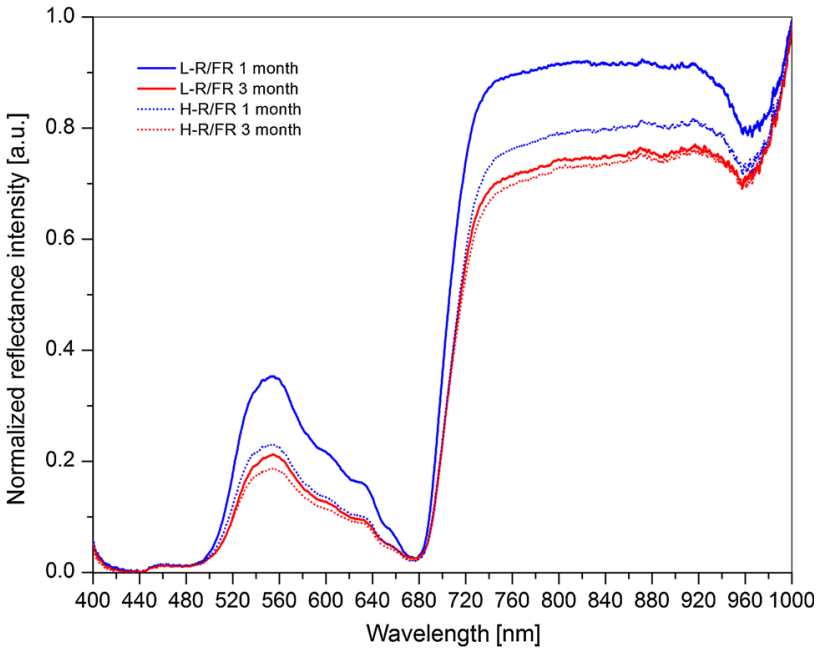

Fig. 5 Light radiation reflectance curves of Platycerium bifurcatum sporotrophophyll leaves after 1 and 3 months of growth at low (L-R/ FR) and high (H-R/FR) red/far-red ratio (R/FR) in the light spectrum. The mean values of 5 replicates

leaves exposed to L-R/FR showed a higher decrease in reflectance intensity than those growing under $\mathrm{H}-\mathrm{R} / \mathrm{FR}$ (Fig. 5). The low reflectance in terms of PAR was associated with the light absorption of plant pigments present in the leaves. Lower reflectance may also lead to the gradual disappearance of tomentose during leaf development, which affects their optical properties (Taiz and Zeiger 2006). All of these factors are changing during leaf development (Araus et al. 2001). Sometimes such differences are related to the adaptation of plants to sunny or shady habitats. This is possible due to the presence of phytochromes, which activity is regulated by the R/FR ratio in the white light spectrum (Smith and Whitelam 1990). Radiation reflectance in the NIR range $(700-1000 \mathrm{~nm})$ is always higher than in the PAR range. Reflectance intensity in this part of the spectrum is conditioned mainly by the tissue spatial structure and ultrastructure of parenchymal cells in the leaf. An important role is played by the relative position of the cell wall and protoplasm as well as spaces between chloroplasts and cell wall and protoplasm (Grant 1987). The intensity of reflectance in the NIR range $950-970 \mathrm{~nm}$ is directly related 
to the degree of cell hydration (Peñuelas et al. 1993). After the first month, higher reflectance values were observed in the plants growing under L-R/FR compared to those under H-R/FR. In both cases, reflectance intensity decreased after 3 months of growth, although this reduction was less pronounced in plants growing under H-R/FR. However, the higher radiation reflectance was still evident in plants under L-R/FR. Lower reflectance after 3 months could also be the result of partial tomentose loss observed during ontogeny.

Changes in carotenoids $\left(\mathrm{CRI}_{1}\right)$, anthocyanins (ARI) and hydration (WBI) of P. bifurcatum leaves, determined based on the reflectance indices are summarized in Table 3. The analysis of carotenoid content is problematic because they are obscured by chlorophylls (Gitelson et al. 2002) and xanthophylls, which alterations are observed during leaf ontogeny and/or acclimation to changing lighting conditions (Gross 1987; Knee 1988; Merzlyak and Solovchenko 2002). The $\mathrm{CRI}_{1}$ parameter increases proportionally to carotenoid content in the tissue (Solovchenko 2010). The amount of carotenoid, estimated on its basis, in the leaves exposed to L-R/FR was higher already after 1 month of growth in comparison with the values recoded in the plants growing under $\mathrm{H}-\mathrm{R} / \mathrm{FR}$. After subsequent 2 months of growth under $\mathrm{L}-\mathrm{R} / \mathrm{FR}$, the reflectance derived from carotenoids was increased, whereas under H-R/FR remained at the same level. Carotenoids, especially zeaxanthin and violaxanthin, play an important role during excess energy dissipation (xanthophyll cycle) and protection of photosynthetic apparatus (Peterman et al. 1997). Moreover, carotenoid molecules are part of the PSII antenna complex located in thylakoid membranes, which development in the shadow may be associated with the need to increase light absorption by the plant. Similar relationship, as for carotenoids, can be observed in the analysis of reflectance derived from anthocyanins. Accumulation of anthocyanins in the leaves is a very common response of plants to environmental impact associated with the change of radiation intensity (Chalker-Scott 1999), as anthocyanins are involved in plant protection against the effects of high PAR radiation (Gould et al. 1995; Merzlyak and Chivkunova 2000). The ARI parameter is a sensitive indicator of anthocyanin content in the leaf, increasing linearly with pigment content (Gitelson et al. 2001; Steele et al. 2009). However, the increase of ARI in Platycerium leaves growing under L-R/FR is difficult to unambiguously explain at the current stage of research.

The PRI index is an alternative form of assessment of photosynthesis quantum yield and PSII efficiency. Its fluctuations are usually associated with changes in xanthophyll cycle and dissipation of excess energy as heat, allowing to protect photosystem against the effects of intense radiation (Naumann et al. 2010; Demmig-Adams and Adams 1996). PRI allows to track changes in the light use efficiency (LUE) in photosynthesis caused by various environmental factors (Gamon et al. 1997). Higher PRI values indicate greater efficiency of the light phase of photosynthesis. A significant increase of PRI was observed in plants growing under $\mathrm{H}-\mathrm{R} / \mathrm{FR}$, and a decrease in the case of L-R/FR (Table 3). PRI seems to be a better indicator of the functioning of PSII with respect to a generalized stress response, which causes a sudden reduction in photosynthesis efficiency (Peñuelas and Filella 1998), than in slow acclimation changes occurring during ontogeny. Moreover, plants grown in the shade, after exposure to intense radiation, can demonstrate deviations in PRI (Gamon et al. 1997). The WBI parameter is a good indicator of water content in green leaves (Peñuelas et al. 1993; Sims and Gamon 2003). WBI values in plants growing under both spectral light compositions, show proper degree of hydration and fall in the upper range of 0.8-1.2 a.u. (Peñuelas et al. 1993).

\section{Conclusions}

1. Platycerium bifurcatum is an interesting experimental material in fern physiology studies.

2. Despite the lack of significant differences in anatomy, already after 4 weeks, morphogenic development of sporotrophophyll leaves of the fern $P$. bifurcatum largely depended on the R/FR ratio in the light spectrum. They showed a limited development of leaf blade size at the increased R/FR value, characteristic for environments with high insolation. A decrease of
Table 3 The values of reflectance factors at 1 and 3 months of growth of Platycerium bifurcatum sporotrophophyll leaves at low (L-R/FR) and high (H-R/FR) red/far-red ratio (R/FR)

\begin{tabular}{llllll}
\hline R/FR ratio & Growth time (month) & \multicolumn{4}{l}{ Reflectance factor } \\
\cline { 3 - 6 } & & CRI & ARI & PRI & WBI \\
\hline L-R/FR & 1 & $0.063 \mathrm{~b}$ & $0.24 \mathrm{a}$ & $-0.006 \mathrm{~b}$ & $1.10 \mathrm{~b}$ \\
& 3 & $0.075 \mathrm{c}$ & $0.61 \mathrm{~b}$ & $-0.023 \mathrm{a}$ & $1.01 \mathrm{a}$ \\
H-R/FR & 1 & $0.040 \mathrm{a}$ & $0.12 \mathrm{a}$ & $-0.030 \mathrm{a}$ & $1.02 \mathrm{a}$ \\
& 3 & $0.041 \mathrm{a}$ & $0.05 \mathrm{a}$ & $-0.007 \mathrm{~b}$ & $1.01 \mathrm{a}$ \\
\hline
\end{tabular}

Values in the column marked with the same letters are not significantly different at $P \leq 0.05$ by Duncan test, $n=5$ 
the maximum photochemical efficiency was observed, and slower energy flow through PSII.

3. Differences resulting from the ontogenetic development and reactions of plants to changes in the R/FR ratio were reflected in the parameters of blue-green and red fluorescence of leaves.

4. The analysis of leaf optical properties indicated higher accumulation of carotenoids and anthocyanins in the leaves of plants grown under the lower R/FR ratio.

Author contribution statement AS designed the research; JO, AS, AK conducted the research and analyzed the data; JO wrote the paper; AS and AK had primary responsibility for the final content. All authors have read and approved the final manuscript.

Open Access This article is distributed under the terms of the Creative Commons Attribution 4.0 International License (http://crea tivecommons.org/licenses/by/4.0/), which permits unrestricted use, distribution, and reproduction in any medium, provided you give appropriate credit to the original author(s) and the source, provide a link to the Creative Commons license, and indicate if changes were made.

\section{References}

Araus JL, Casadesus J, Bort J (2001) Recent tools for the screening of physiological traits determining yield. In: Reynolds MP, OrtizMonasterio JI, McNab A (eds.) Application of physiology in wheat breeding, CIMMYT, Mexico, p 59-77. ISBN:970-648077-3

Aspiras RA (2010) Sporophyte and gametophyte development of Platycerium coronarium (Koenig) Desv. and P. grande (Fee) C. Presl. (Polypodiaceae) through in vitro propagation. Saudi J Biol Sci 17:13-22. doi:10.1016/j.sjbs.2009.12.003

Bilger W, Johnsen T, Schreiber U (2001) UV-excited chlorophyll fluorescence as a tool for the assessment of UV-protection by the epidermis of plants. J Exp Bot 52:2007-2014. doi:10.1093/ jexbot/52.363.2007

Bjorkman O, Demming B (1987) Photon yield of $\mathrm{O}_{2}$ evolution and chlorophyll fluorescence characteristics at $77 \mathrm{~K}$ among vascular plants of diverse origins. Planta 170:489-504. doi:10.1007/ BF00402983

Buschmann C, Lichtenthaler HK (1998) Principles and characteristics of multi-colour fluorescence imaging of plants. J Plant Physiol 152:297-314. doi:10.1016/S0176-1617(98)80144-2

Castro FA, Campostrini E, Toress Netto A, Viana LH (2011) Relationship between photochemical efficiency (JIP-Test Parameters) and portable chlorophyll meter readings in papaya plants. Braz J Plant Physiol 23:295-304. doi:10.1590/S1677-042020 11000400007

Chalker-Scott L (1999) Environmental significance of anthocyanins in plant stress responses. Photochem Photobiol 70:1-9. doi:10. 1111/j.1751-1097.1999.tb01944.x

D'Ambrosio N, Szabo K, Lichtenthaler HK (1992) Increase of the chlorophyll fluorescence ratio F685/F735 during the autumnal chlorophyll breakdown. Radiat Environ Bioph 31:51-62. doi:10. 1016/S0034-4257(99)00023-1

Demmig-Adams B, Adams WW (1996) The role of xanthophyll cycle carotenoids in the protection of photosynthesis. Trends Plant Sci 1:21-26. doi:10.1016/S1360-1385(96)80019-7
Fankhauser C (2001) The phytochromes a family of red/far-red absorbing photoreceptors. J Biol Chem 276:11453-11456. doi:10.1186/gb-2008-9-8-230

Force L, Critchley C, van Rensen JJS (2003) New fluorescence parameters for monitoring photosynthesis in plants. Photosynth Res 78:17-33. doi:10.1023/A:1026012116709

Gamon JA, Penuelas J, Field CB (1992) A narrow-waveband spectral index that tracks diurnal changes in photosynthetic efficiency. Remote Sens Environ 41:35-44. doi:10.1016/0034-4257(92)90059-S

Gamon JA, Serrano L, Surfus J (1997) The photochemical reflectance index: an optical indicator of photosynthetic radiation-use efficiency across species, functional types and nutrient levels. Oecologia 112:492-501. doi:10.1007/s004420050337

Gitelson A, Buschmann C, Lihtentahler HK (1998) Leaf chlorophyll fluorescence corrected for re-absorption by means of absorption and reflectance measurements. J Plant Physiol 152:283-296. doi:10.1016/S0176-1617(98)80143-0

Gitelson AA, Merzylak MN, Chivkunova OB (2001) Optical properties and nondestructive estimation of anthocyanin content in plant leaves. Photochem Photobiol 71:38-45. doi:10.1562/ 0031-8655(2001)074<0038:OPANEO > 2.0.CO;2

Gitelson AA, Zur Y, Chivkunova OB, Merzylak MN (2002) Assessing carotenoid content in plant leaves with reflectance spectroscopy. Photochem Photobiol 75:272-281. doi:10.1562/ 0031-8655(2002)s0750272ACCIPL2.0.CO2

Gould KS, Kuhn DN, Lee DW, Oberbauer SF (1995) Why leaves are sometimes red. Nature 378:241-242. doi:10.1038/378241b0

Grant L (1987) Diffuse and specular characteristics of leaf reflectance. Remote Sens Environ 22:309-322. doi:10.1016/ 0034-4257(87)90064-2

Gross J (1987) Carotenoids: pigments in fruits. Food science and technology. Series of monographs. Academic, London, pp 87-98

Hall DO, Rao KK (1999) Photosynthesis, 6th edn. Cambridge University, Cambridge. ISBN 9780521644976

Jiang CD, Jiang GM, Wang X, Li LH, Biswas DK (2006) Increased photosynthetic activities and thermostability of photosystem II with leaf development of elm seedlings (Ulmus pumila) probed by the fast fluorescence rise OJIP. Environ Exp Bot 58:261-268. doi:10.1016/j.envexpbot.2005.09.007

Johnson GA, Mantha SV, Day TA (2000) A spectrofluorometric survey of UV-induced blue-green fluorescence in foliage of 35 species. J Plant Physiol 156:242-252. doi:10.1016/S01761617(00)80313-2

Jones D, Goudey C (1981) Ferns in Australia common rare and exotic. Reed Books Pty. Ltd. Frenchs Forest NSW, Sydney, p 20 ISBN:0730100065

Kawai H, Kanegae T, Christensen S, Kiyosue T, Sato Y, Imaizumi T, Kadota A, Wada M (2003) Responses of ferns to red light are mediated by an unconventional photoreceptor. Nature 421:287-290. doi:10.1038/nature01310

Kircher S, Kozma-Bognar L, Kim L, Adam E, Harter K, Schäfer E, Nagy F (1999) Light quality-dependent nuclear import of the plant photoreceptors phytochrome A and B. Plant Cell 11:1445-1456. doi:10.1105/tpc.11.8.1445

Knee M (1988) Carotenol esters in developing apple fruits. Phytochemistry 27:1005-1009. doi:10.1016/0031-9422(88)80261-9

Kraepiel Y, Agnès C, Thiery L, Maldiney R, Miginiac E, Delaure M (2001) The growth of tomato (Lycopersico esculentum Mill.) hypocotyls in the light and in darkness differentially involves auxin. Plant Sci 161:1067-1074. doi:10.1016/S0168-9452(01)00495-2

Kreier HP, Schneider H (2006) Phylogeny and biogeography of the staghorn fern genus Platycerium (Polypodiaceae, Polypodiidae). Am J Bot 93:217-225. doi:10.3732/ajb.93.2.217

Lambers H, Stuart Chapin F III, Pons H (2008) Plant physiological ecology. Springer Science, New York, pp 29-32. ISBN 978-0387-78340-6 
Liao YK, Wu YH (2011) In vitro propagation of Platycerium bifurcatum (Cav.) C. Chr. via green globular body initiation. Bot Stud 52:455-463

Lichtenthaler HK, Schweiger J (1998) Cell wall bound ferulic acid the major substance of the blue-green fluorescence emission of plants. J Plant Physiol 152:272-282. doi:10.1016/S0176-1617 (98)80142-9

Lichtenthaler HK, Buschmann C, Rinderle U, Schmuck G (1986) Application of chlorophyll fluorescence in ecophysiology. Radiat Environ Biophys 25:297-308. doi:10.1007/BF01214643

Merzlyak MN, Chivkunova OB (2000) Light stress induced pigment changes and evidence for anthocyanin photoprotection in apple fruit. J Photochem Photobiol 55:154-162. doi:10.1016/S10111344(00)00042-7

Merzlyak M, Solovchenko A (2002) Photostability of pigments in ripening apple fruit: a possible photoprotective role of carotenoids during plant senescence. Plant Sci 163:881-888. doi:10.1016/S0168-9452(02)00241-8

Moya I, Cerovic ZG (2004) Remote sensing of chlorophyll fluorescence: instrumentation and analysis. In: Papageorgiou GC, Govindjee (eds.) Chlorophyll $a$ fluorescence: a signature of photosynthesis. Springer, Netherlands, p 429-445. doi:10.1007/ 978-1-4020-3218-9

Nadkarni NM, Parker GG, Rinker HB, Jarzen DB (2004) The nature of forest canopy. In: Lowman MD, Rinker HB (ed) Forest Canopies, Academic Press, USA, p 3-10. ISBN:10:0-12457553-6

Naumann JC, Young DR, Anderson JE (2008) Leaf chlorophyll fluorescence reflectance and physiological response to freshwater and saltwater flooding in the evergreen shrub Myrica cerifera. Environ Exp Bot 63:402-404. doi:10.1016/j.envexpbot.2007.12. 008

Naumann JC, Anderson J, Young DR (2010) Remote detection of plant physiological responses to TNT soil contamination. Plant Soil 329:239-248. doi:10.1007/s11104-009-0148-1

Neff MM, Fankhauser C, Chory J (2000) Light: an indicator of time and place. Genes Dev 14:257-271. doi:10.1101/gad.14.3.257

Oguchi R, Hikosaka K, Hirose T (2005) Leaf anatomy as a constraint for photosynthetic acclimation: differential responses in leaf anatomy to increasing growth irradiance among three deciduous trees. Plant Cell Environ 28:916-927. doi:10.1111/j.1365-3040. 2005.01344.x

Oliveira JG, Alves PLCA, Magalhăes ACN (2002) The effect of chilling on the photosynthetic activity in coffee (Coffea arabica L.) seedlings. The protective action of chloroplastid pigments. Braz J Plant Physiol 14:95-104. doi:10.1590/S1677-0420200 2000200003

Paiva LB, Oliveira JG, Azevedo RA, Ribeiro DR, Silva MG, Vitória AP (2009) Ecophysiological responses of water hyacinth exposed to $\mathrm{Cr}^{+3}$ and $\mathrm{Cr}^{+6}$. Environ Exp Bot 65:403-409. doi:10.1016/j.envexpbot.2008.11.012

Peñuelas J, Filella I (1998) Visible and near-infrared reflectance techniques for diagnosing plant physiological status. Trends Plant Sci 3:151-156. doi:10.1016/S1360-1385(98)01213-8

Peñuelas J, Filella I, Biel C, Serrano L, Save R (1993) The Reflectance at the 950-970 region as an indicator of plant water status. Int J Remote Sens 14:1887-1905. doi:10.1080/0143116 9308954010

Pereira WE, Siqueira DL, Martínez CA, Puiatti M (2000) Gas exchange and chlorophyll fluorescence in four citrus rootstocks under aluminium stress. J Plant Physiol 157:513-520. doi:10. 1016/S0176-1617(00)80106-6

Peterman EJG, Gradinaru CC, Calkoen F, Borst JC, van Grondelle R, van Amerongen $\mathrm{H}$ (1997) Xanthophylls in light-harvesting complex II of higher plants: light harvesting and triplet quenching. Biochemistry 36:12208-12215. doi:10.1021/bi9711 689

Quail PH (1994) Photosensory perception and signal transduction in plants. Curr Opin Genet Dev 4:652-661. doi:10.1016/0959437X(94)90131-L

Richter PI, Lichtenthaler HK (1996) Concept of application of synthetic optical spectra in photobiological research of plants. J Plant Physiol 148:464-470. doi:10.1016/S0176-1617(96) 80280-X

Rösler J, Jaedicke K, Zeidler M (2010) Cytoplasmic phytochrome action. Plant Cell Physiol 51:1248-1254. doi:10.1093/pcp/pcq091

Rut G, Krupa J, Rzepka A (2003) The influence of simulated osmotic drought on functioning of the photosynthetic apparatus in gametophytes of the epiphytic fern Platycerium bifurcatum. Pol J Nat Sci Supplement 1:144-145

Sanusi R-AM, Nuruddin AA, Hamid HA (2011) Leaf chlorophyll fluorescence and gas exchange response to different light levels in Platycerium bifurcatum. Am J Agri Biol Sci 6:214-220. doi:10.3844/ajabssp.2011.214.220

Schweiger J, Lang M, Lichtenthaler HK (1996) Differences in fluorescence excitation spectra of leaves between stressed and non-stressed plants. J Plant Physiol 148:537-547. doi:10.1016/ S0176-1617(96)80073-3

Sims DA, Gamon JA (2003) Estimation of vegetation water content and photosynthetic tissue area from spectral reflectance: a comparison of indices based on liquid water and chlorophyll absorption features. Remote Sens Environ 84:526-537. doi:10. 1016/S0034-4257(02)00151-7

Smith H, Whitelam GC (1990) Phytochrome a family of photoreceptors with multiple physiological roles. Plant Cell Environ 13:695-707. doi:10.1111/j.1365-3040.1990.tb01084.x

Solovchenko A (2010) Quantification of screening pigments and their efficiency in situ. In: Solovchenko A Photoprotection in Plants. Springer Ser. in Biophysics 14, Springer-Verlag Berlin, Heidelberg. doi:10.1007/978-3-642-13887-4_6

Steele M, Gitelson A, Rundquist D, Merzlyak M (2009) Nondestructive estimation of anthocyanin content in grapevine leaves. Am J Enol Vitic 60:87

Stober F, Lichtenthaler HK (1993) Characterisation of the laser-induced blue, green and red fluorescence signatures of leaves of wheat and soybean leaves grown under different irradiance. Physiol Plant 88:696-704. doi:10.1111/j.1399-3054.1993.tb01391.x

Strasser RJ, Srivastava A and Tsimilli-Michael M (2000) The fluorescence transient as a tool to characterize and screen photosynthetic samples. In: Yunus M, Pathre U and Mohanty P (eds.) Probing Photosynthesis: Mechanism, Regulation and Adaptation, Chapter 25. Taylor and Francis, London, UK, p 443-480. doi:10.1023/A:1013740030762

Strasser RJ, Tsimilli-Michael M, Srivastava A (2004) Analysis of the chlorophyll $a$ fluorescence transient. In: Papageorgiou GC, Govindjee (eds.) Chlorophyll $a$ fluorescence: a signature of photosynthesis. Springer, Netherlands, p 321-362. doi:10.1007/ 978-1-4020-3218-9

Taiz L, Zeiger E (2006) Plant physiology, 4th edn. Sinauer Associates, Sunderland

Tuba Z, Lichtenthaler HK, Csintalan Z, Pocs T (1993) Regreening of desiccated leaves of the poikilochlorophyllous Xerophyta scabrida upon rehydration. J Plant Physiol 142:103-108. doi:10.1016/S0176-1617(11)80115-X

Vogelmann TC, Nishio JN, Smith WK (1996) Leaves and light capture: light propagation and gradients of carbon fixation within leaves. Trends Plant Sci 1:65-70. doi:10.1016/S1360-1385(96) 80031-8

Wada M (1988) Chloroplast photoorientation in enucleated fern protonemata. Plant Cell Physiol 29:1227-1232 